\title{
Nanometric multilayers: A new approach for joining TiAl
}

\author{
A.S. Ramos ${ }^{\text {a }}$, M.T. Vieira ${ }^{\text {a } *}$, L.I. Duarte ${ }^{\text {b }}$, M.F. Vieira ${ }^{\text {b }}$, F. Viana ${ }^{\text {b }}$, R. Calinas ${ }^{a}$ \\ ${ }^{a}$ ICEMS, Departamento de Engenharia Mecânica, Faculdade de Ciências e Tecnologia, Universidade de Coimbra, \\ R. Luís Reis Santos, 3030-788 Coimbra, Portugal \\ ${ }^{\mathrm{b}}$ GMM/IMAT, Departamento de Engenharia Metalúrgica, Faculdade de Engenharia, Universidade do Porto, 4200-465 Porto, Portugal
}

Received 5 September 2005; received in revised form 1 December 2005; accepted 20 December 2005

Available online 20 March 2006

\begin{abstract}
A novel intermetallic alloy diffusion bonding procedure is being developed. The innovative aspect relies on the use of sputtered nanometallic multilayers made up of the elements present in the bulk intermetallics to enhance the bonding mechanisms. For this purpose a deep knowledge of the multilayer thin films is required, focusing on thermal phase stability and grain size evolution. $\gamma$-TiAl was selected for this study and Ti/Al multilayer thin films with nanometric period $(\Lambda=4 \mathrm{~nm})$ were deposited onto Ti- $(45-49) \mathrm{Al}-(3-2) \mathrm{Nb}-2 \mathrm{Cr}$ (at.\%) substrates by d.c. magnetron sputtering. The as-deposited titanium and aluminium nanolayers with crystallite sizes of 5-50 nm evolve toward the equilibrium $\gamma$-TiAl structure after heat treatment for at least up to $600{ }^{\circ} \mathrm{C}$ at a $10{ }^{\circ} \mathrm{C} \mathrm{min}-1$ heating rate. Whatever the heating temperature and holding time, between 600 and $1000{ }^{\circ} \mathrm{C}$, the $\gamma$-TiAl phase is stable. During the thermal cycle the growth of the nanometric grains is promoted, this effect being more pronounced as the temperature and holding time increase. Consequently, the hardness decreases from $11.9 \mathrm{GPa}\left(600{ }^{\circ} \mathrm{C}, 1 \mathrm{~h}\right)$ to $6.5 \mathrm{GPa}$ $\left(1000{ }^{\circ} \mathrm{C}, 3 \mathrm{~h}\right)$. This study allowed the thermal treatment required to join $\gamma$-TiAl parts to be established.
\end{abstract}

(C) 2006 Elsevier Ltd. All rights reserved.

Keywords: A. Titanium aluminides, based on TiAl; A. Nanostructured intermetallics; B. Surface properties; C. Thin films; C. Joining

\section{Introduction}

As widely reported in the literature titanium aluminides based on the intermetallic phase of $\gamma$-TiAl are promising materials for high temperature applications [1,2]. However, due to their low room temperature ductility these materials are difficult to manufacture: shape forming and joining. Thus, it is reasonable to develop strategies for the deposition of thin films based on titanium aluminides [3]. During the last decade, the authors have used $\mathrm{Ti}-\mathrm{Al}$ system thin films as predictive alloys, first for developing new doping strategies and secondly to evaluate their physical and chemical properties for new applications [4,5]. The properties of $\mathrm{Ti}-\mathrm{Al}$ based thin films, as-deposited and heat treated, were previously evaluated $[6,7]$. As a result of these studies, a novel application of

\footnotetext{
* Corresponding author. Tel.: +351 239790700; fax: +351 239790701. E-mail address: teresa.vieira@dem.uc.pt (M.T. Vieira).
}

$\mathrm{Ti}-\mathrm{Al}$ thin films to promote sustainable and sound joining between intermetallic compounds is proposed.

In order to increase the applicability of titanium aluminides it is necessary to develop joining technologies capable of producing complex shapes from simple assemblies. Solid-state diffusion bonding [8-11] and diffusion brazing [12] seem to be the most straightforward techniques for producing joints with mechanical properties similar to those of $\gamma$-TiAl alloys at high temperatures. Diffusion bonding causes less disruption of the components to be joined and more homogeneous interfaces than does diffusion brazing. In solid-state diffusion bonding, which is the simplest diffusion bonding technique, the bond strength is improved by the occurrence of dynamic recrystallisation at the bond-line, but the temperature of the process is usually as high as 0.8 of the absolute melting temperature of the material being joined, while the pressure depends on whether it is applied uniaxially or isostatically $[8,13]$. In the former case, a low pressure (usually $3-10 \mathrm{MPa}$ ) is used to avoid macrodeformation. In hot isostatic pressing (HIP), much higher 
pressures (up to $200 \mathrm{MPa}$ ) can be used and the surface finishing is not as critical as in the uniaxial case $[8,14]$. The holding times at elevated temperatures can range from minutes to a few hours, depending on the material, joint properties required and remaining bonding parameters. To assist in the joining process it is also possible to introduce interlayers between the materials to be joined. These interlayers are usually pure and soft metals, introduced as thick or thin foils.

A novel approach to the solid-state diffusion bonding of $\gamma$ TiAl alloys consists of introducing sputtered Ti/Al multilayer thin films as interlayer materials. Ti/Al multilayer thin films with nanometric periods deposited onto TiAl substrates, associated to their nanocrystalline structure, could increase the diffusivity and reactivity of the surfaces being joined. Using this innovative procedure, disruptions between the interlayers and the materials being joined are avoided. Moreover, the exothermic character of the metallic multilayer thin film's thermal evolution towards the $\gamma$-TiAl phase contributes to a decrease in the energy required for the bonding process.
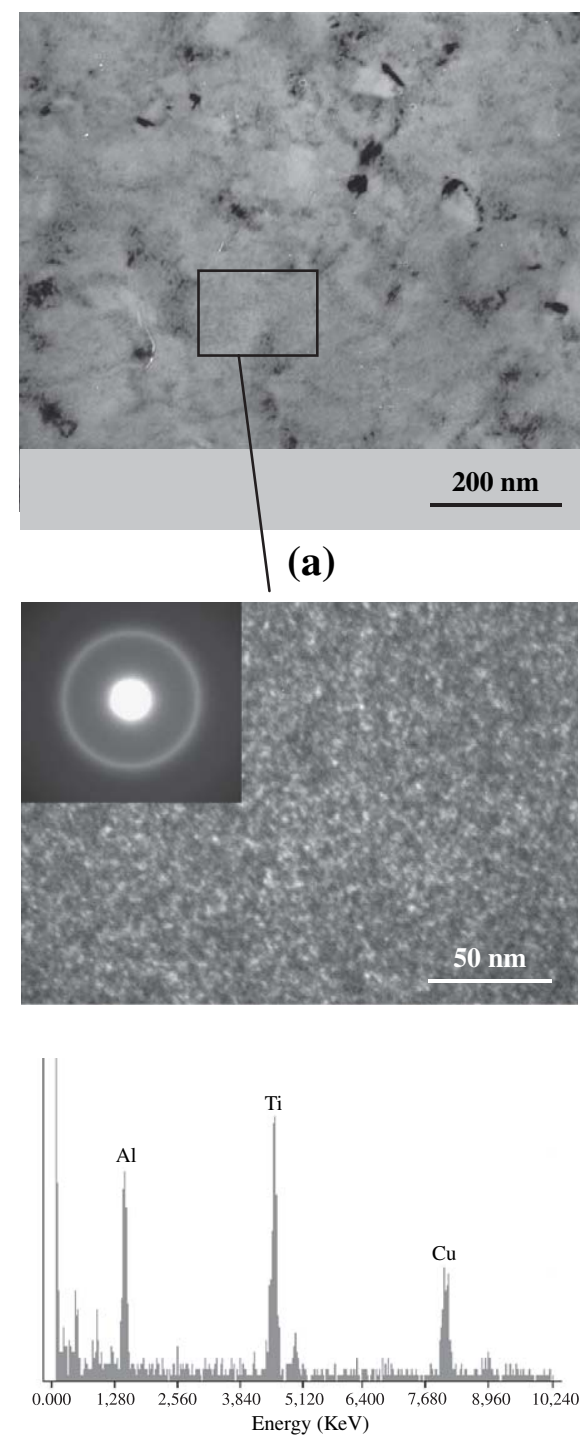

The aim of this study is to establish a new paradigm for the joining of intermetallics. In order to attain this goal this study focused on the joining of $\gamma$-TiAl using multilayer thin films of the main chemical elements of the bulk materials. To estimate the performance of the joints, studies of the thin films' grain size and hardness evolution within the bonding thermal cycle were performed.

\section{Experimental details}

\subsection{Materials}

Two $\gamma$-based titanium aluminide bulk materials were used in this study: alloy $\mathrm{A}$ and $\mathrm{B}$ with chemical compositions (at.\%) of $45.1 \mathrm{Al}-2.0 \mathrm{Cr}-2.1 \mathrm{Nb}$ and $49.1 \mathrm{Al}-1.8 \mathrm{Cr}-3.2 \mathrm{Nb}$, respectively. In $\mathrm{A}$ the presence of a minor $\alpha_{2}-\mathrm{Ti}_{3} \mathrm{Al}$ phase together with the $\gamma$-TiAl phase was identified by X-ray diffraction (XRD). This $\gamma$-TiAl base material has a duplex microstructure with micrometric $\gamma$ equiaxed $(\sim 30 \mu \mathrm{m})$ grains and

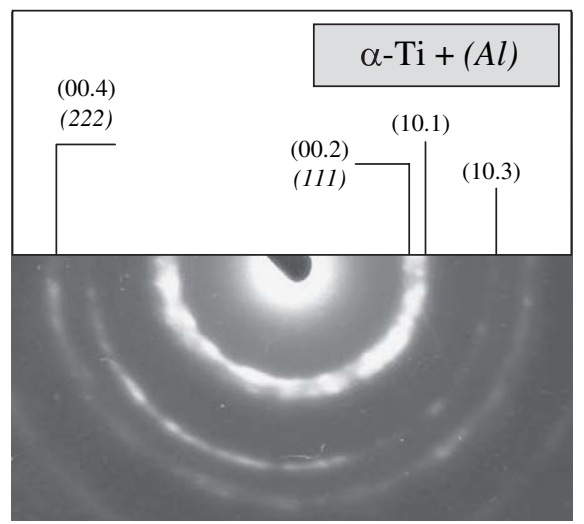

(b)

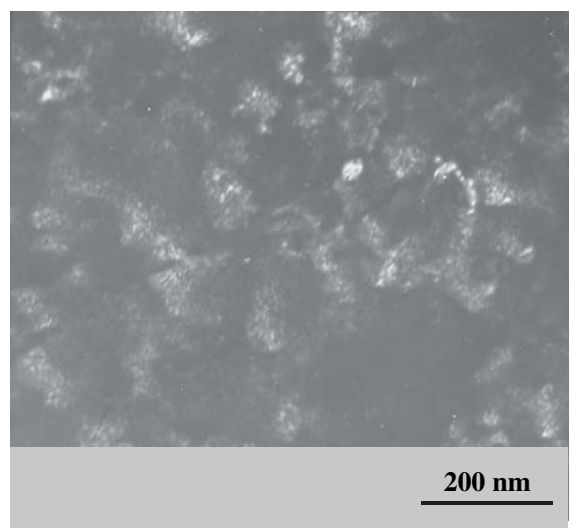

(c)

Fig. 1. TEM micrographs of as-deposited Ti/Al multilayer thin film: (a) BF image and higher magnification DF image with the respective SAD pattern and EDX analysis, (b) SAD pattern and (c) corresponding DF image. 
larger $\gamma-\mathrm{TiAl} / \alpha_{2}-\mathrm{Ti}_{3} \mathrm{Al}(\sim 70 \mu \mathrm{m})$ lamellar grains. In $\mathrm{B}$ after etching the grain boundaries are not visible, as the $\gamma$ grains are undefined. The $\gamma$-TiAl alloys were diamond polished after being mechanically ground to a 1200 grit finish and cleaned in an ultrasonic bath with acetone and ethanol before entering into the deposition chamber. Some samples were also used in the as-ground condition.

\subsection{Interlayer thin films}

Ti/Al multilayer thin films were deposited onto $\gamma$-TiAl substrates by d.c. magnetron sputtering using two pure metallic targets ( $\mathrm{Al}$ and Ti). The $\mathrm{Al}$ target operated at $2.2 \times 10^{-4} \mathrm{~W} \mathrm{~mm}^{-2}$ and the titanium target power supply was adjusted in order to have the desired overall chemical composition. The total multilayer thickness is close to $2-3 \mu \mathrm{m}$. The thin films produced were characterised in the as-deposited state and after heat treatment at different temperatures and holding times in a hydrogenated argon atmosphere.

The chemical composition of the thin films was determined by electron probe microanalysis using a Cameca SX50 apparatus. Microstructural analyses were performed by transmission electron microscopy (TEM) using a Hitachi H-8100 operating at an acceleration voltage of $200 \mathrm{keV}$. This instrument is equipped with energy dispersive X-ray (EDX) analysis with a $50 \mathrm{~nm}$ probe. Thin films for TEM analysis were supported between two copper grids and thinned on both sides to electron transparency by ion milling under an argon atmosphere or by standard electropolishing with a solution of 5\% perchloric acid, 35\% ethylenglycol and 60\% methanol at $15 \mathrm{~V}$. To analyse the state of the as-deposited films and identify the structural changes with temperature, XRD was carried out with a Philips $\mathrm{X}$-PERT diffractometer using Co $\mathrm{K} \alpha$ radiation. The evolution of the samples as they were submitted to elevated temperature was monitored by differential scanning calorimetry (DSC) using a Setaram Setsys 1750 evolution equipment. The hardness of the thin films was evaluated on a computer controlled Fisherscope H100 ultramicrohardness tester, equipped with a Vickers diamond indenter, using a $30 \mathrm{mN}$ load.

\subsection{Solid-state diffusion bonding with interlayer}

Thin foils for transmission electron microscopy were prepared from the bonded samples. For TEM analysis diffusion bonded samples were cut and their thickness reduced by hand grinding and polishing. Then, discs $3 \mathrm{~mm}$ in diameter were cut and thinning was completed electrochemically.

\section{Results and discussion}

\subsection{Interlayer thin films}

The Ti/Al multilayer thin films have an overall chemical composition close to 48 at.\% of aluminium. The layered structure results from the time that the substrates under rotation pass in front of each target during the deposition process, being the

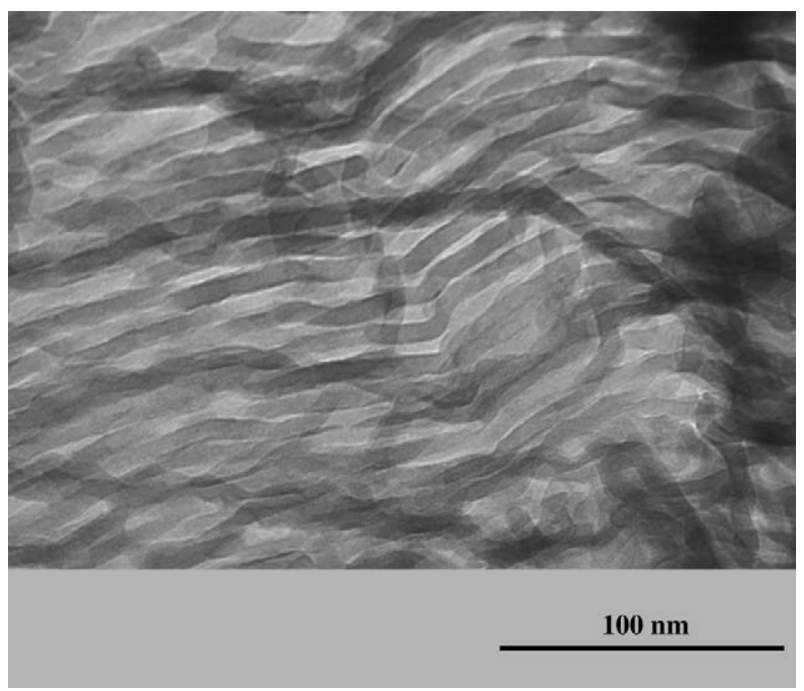

Fig. 2. TEM top view image of an as-deposited Ti/Al multilayer thin film. Dark-grey layers correspond to Ti-rich phase and light-grey layers to Al-rich phase.

Ti and Al single layer thickness a function of the substrates' rotation speed. The multilayer consists of two solid solutions, one Ti-rich $(\alpha-\mathrm{Ti})$ and the other Al-rich $(\mathrm{Al})$ with nanometric grain sizes. Fig. 1(a) and (c) presents bright-field (BF) and dark-field (DF) TEM images of an as-deposited Ti/Al multilayer thin film, respectively. The DF image was recorded by centring of the (111) $\mathrm{Al} /(00.2)$ Ti rings (Fig. 1(b)) which are coincident (for other rings corresponding to planes with lower interplanar distances the luminosity was insufficient). BF and DF images show a matrix with embedded fine precipitates ( $\mathrm{Ti}$ or Al nanocrystallites). The selection-area diffraction (SAD) pattern (insert in Fig. 1(a)) indicates a reduced crystallinity, and an almost equiatomic chemical composition was revealed by EDX. The nanolayered structure of the top of as-deposited thin films is illustrated in Fig. 2, where $\mathrm{Ti}$ and $\mathrm{Al}$ layers could be identified. As already observed for higher period multilayers [15], the titanium layers are thicker than the aluminium ones due

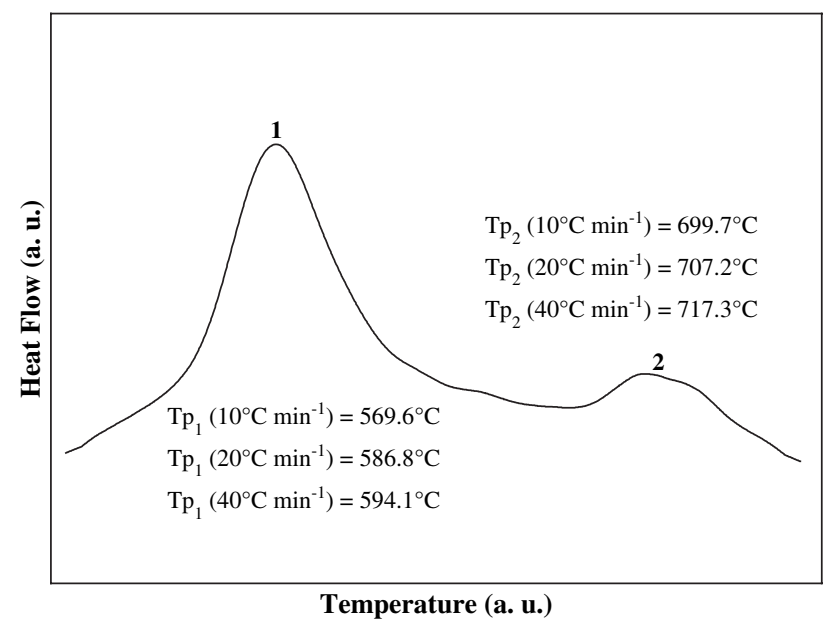

Fig. 3. Typical DSC curve of Ti/Al multilayer thin films with $4 \mathrm{~nm}$ period and influence of the heating rate on the peak temperature, Tp. 


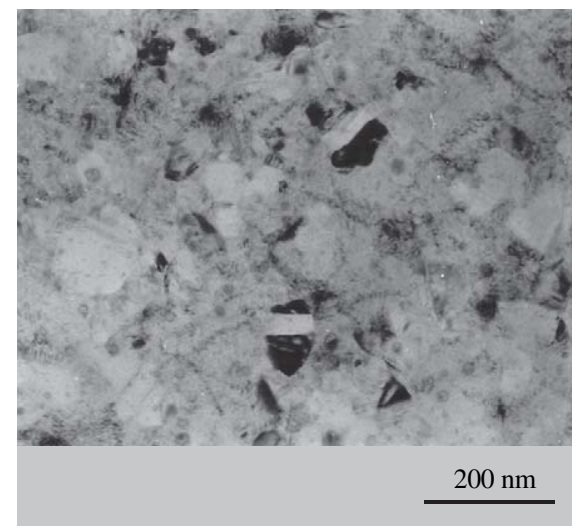

(a)

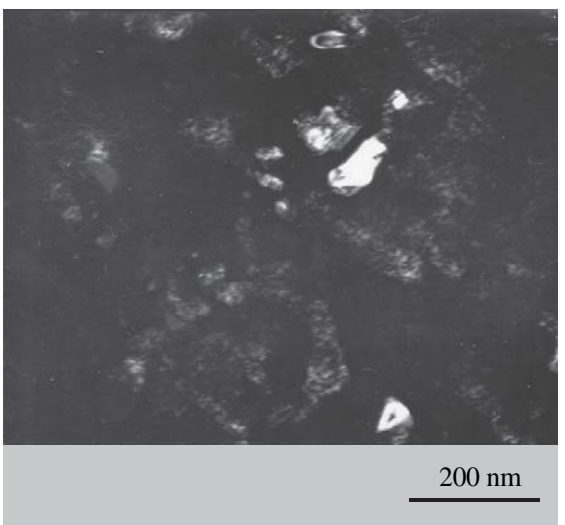

(c)

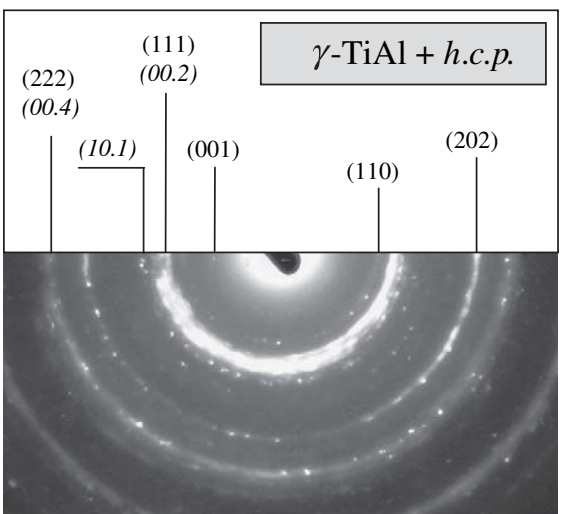

(b)

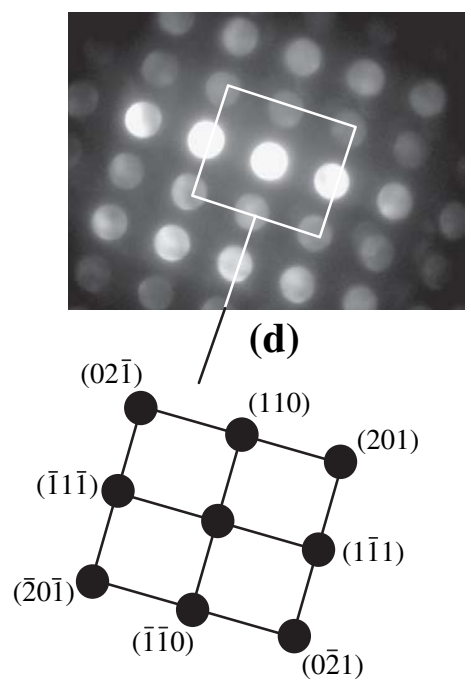

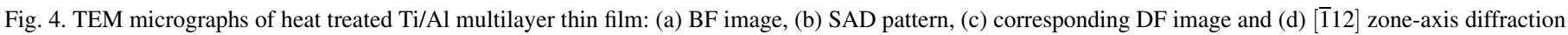
pattern.

to the diffusion of $\mathrm{Al}$ into the $\mathrm{Ti}$ layers at the deposition temperature.

Due to the usual metastable as-deposited structures, the study of the structural evolution of the $\mathrm{Ti}-\mathrm{Al}$ films towards the equilibrium assumes particular relevance. During heat treatment, Ti/Al multilayer films with nanometric periods evolve towards equilibrium due to $\mathrm{Ti}$ and $\mathrm{Al}$ interdiffusion and reaction. The lower the period the more favoured the formation of intermetallic reaction products should be. In fact, the initial state at an interface between two elements with a tendency for compound formation is a non-equilibrium situation and the driving forces for interdiffusion and reaction are extremely high. The reaction between $\mathrm{Ti}$ and $\mathrm{Al}$ is highly exothermic. The Ti/Al multilayer thin films under study transform into $\gamma$-TiAl during $1 \mathrm{~h}$ of heat treatment at $600{ }^{\circ} \mathrm{C}$. The curve in Fig. 3 is an example of the DSC thermograms of Ti/Al multilayers with $4 \mathrm{~nm}$ period heated up to $800{ }^{\circ} \mathrm{C}$. Two exothermic peaks were observed and, as expected, the peak temperature $\left(T_{p}\right)$ increases with the heating rate (Fig. 3). XRD analyses performed after DSC runs up to the first peak off-set temperature were indexed as ordered $\gamma$-TiAl, without and with small amounts of $\alpha_{2}-\mathrm{Ti}_{3} \mathrm{Al}$. Therefore, peak 1 should contain the all phase evolution sequence Ti/Al multilayers $\rightarrow$ disordered $\mathrm{TiAl} \rightarrow \gamma-\mathrm{TiAl}+\alpha_{2}-\mathrm{Ti}_{3} \mathrm{Al}$ (traces). While the first peak should correspond to the nucleation of the reaction product(s) and coalescence into a continuous layer, the second peak could be interpreted as the thickening of the $\gamma$-TiAl layer.

It should be noted that once the $\gamma$-TiAl equilibrium phase is formed, no more structural phase evolutions were detected during isothermal heat treatments at 600,800 and $1000{ }^{\circ} \mathrm{C}$.

Hampshire et al. [16] also reported that at $600{ }^{\circ} \mathrm{C} \mathrm{Ti} / \mathrm{Al}$ multilayer thin films with periods between 3 and $25 \mathrm{~nm}$ transformed into a $\gamma$-TiAl single-phase structure. For higher periods, Michaelsen et al. [17] observed a $\mathrm{TiAl}_{3}$ intermediate phase, formed at $450{ }^{\circ} \mathrm{C}$, with the subsequent formation of $\gamma$-TiAl after heating at $700{ }^{\circ} \mathrm{C}$, indicating that the multilayer with a $50 \mathrm{~nm}$ period had also fully reacted.

$\mathrm{BF}$ and DF TEM images of a multilayer thin film heat treated at $600{ }^{\circ} \mathrm{C}$ for $1 \mathrm{~h}$ are presented in Fig. 4(a) and (c), respectively. The DF image was recorded by centring of the (111) $\gamma$-TiAl ring (Fig. 4(c)) which coincides with the (00.2) ring of a minor h.c.p. phase indexed as $\alpha_{2}-\mathrm{Ti}_{3} \mathrm{Al}$. In fact, EDX analysis revealed Ti and $\mathrm{Al}$ similar contents, but in very few points higher Ti contents (>60 at.\%) were detected, indicating the presence of a Ti-rich 
Table 1

Hardness (GPa) of heat treated Ti/Al multilayer thin films

\begin{tabular}{llcl}
\hline Time & \multicolumn{3}{l}{ Temperature } \\
\cline { 2 - 4 } & $600{ }^{\circ} \mathrm{C}$ & $800^{\circ} \mathrm{C}$ & $1000{ }^{\circ} \mathrm{C}$ \\
\hline $1 \mathrm{~h}$ & 11.9 & 11.3 & 8.0 \\
$3 \mathrm{~h}$ & 10.9 & 9.0 & 6.5 \\
\hline
\end{tabular}

phase. Nevertheless, it was not possible to perform nano-diffraction of this phase. The heat treated crystallite size allowed nanodiffraction of single $\gamma$ grains to be performed as illustrated in Fig. 4(d). During the heat treatment the grain growth is promoted as can be confirmed by the TEM images in Fig. 4. After $1 \mathrm{~h}$ annealing, grain sizes in the range $50-100 \mathrm{~nm}$ were observed. Further grain size growth can be achieved by increasing the heat treatment temperature and/or holding period [5]. The grain size influences the hardness, whose values are summarised in Table 1. After the formation of $\gamma$-TiAl from Ti and Al the holding time contributes to a decrease in the hardness (Table 1) and an improved ductility [7]. For the same holding time, increasing the heat treatment temperature leads also to a hardness decrease.

Due to the evolution towards the $\gamma$-TiAl phase, these films show promise for use as interlayers in the diffusion bonding of $\gamma$ alloys. In fact, at the bonding temperatures, the interlayer and base materials will have a major $\gamma$-phase, avoiding material disruptions and also the need for post-bond heat treatments usually required when pure metallic films are used as interlayers [14].

\subsection{Solid-state diffusion bonds}

To ensure that at $600{ }^{\circ} \mathrm{C}$ the reaction between $\mathrm{Ti}$ and $\mathrm{Al}$ is almost completed and according to the DSC results, the diffusion bonding experiments were conducted at a $10{ }^{\circ} \mathrm{C} \mathrm{min}{ }^{-1}$ heating rate. The solid-state diffusion bonding at $600{ }^{\circ} \mathrm{C} /$ $50 \mathrm{MPa} / 1 \mathrm{~h}$ of $\mathrm{Ti}-45 \mathrm{Al}-2 \mathrm{Nb}-2 \mathrm{Cr}$ alloys coated with $\mathrm{Ti} / \mathrm{Al}$ multilayer thin films allowed joints to be produced with some zones free of micropores (not even nanopores) or cracks where the bonding was effective. By EDS analysis it was possible to detect in the contact zone the presence of a Ti-rich phase, probably $\alpha_{2}-\mathrm{Ti}_{3} \mathrm{Al}$. Buque et al. [18] have already reported the presence of $\alpha_{2}-\mathrm{Ti}_{3} \mathrm{Al}$ due to the surface contamination with oxygen. The remaining thin film had an overall chemical composition close to 49 at.\% of Al. $\gamma$-TiAl joints by solid-state diffusion bonding have been produced at a low temperature such as $600{ }^{\circ} \mathrm{C}$ [19]. However, using this procedure it was not possible to join alloy $\mathrm{B}$ at this temperature. Different mechanical

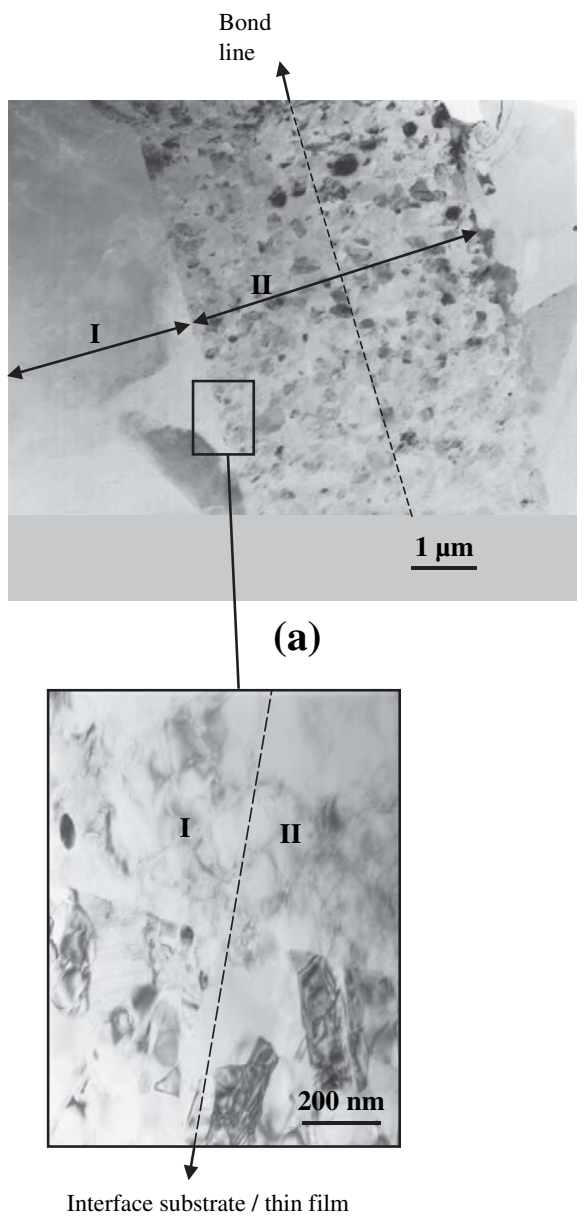

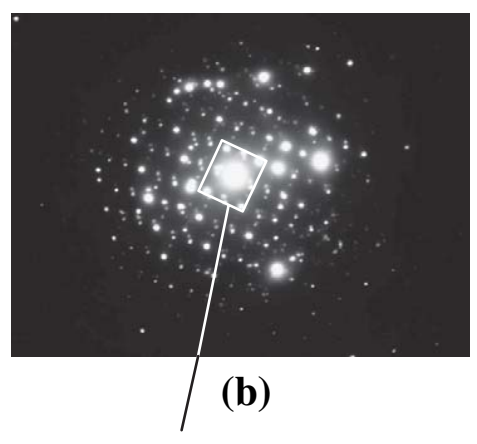

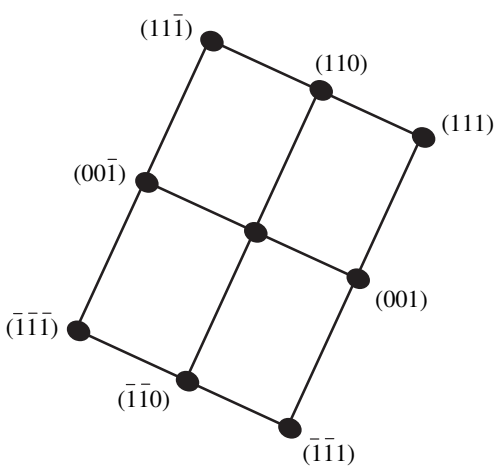

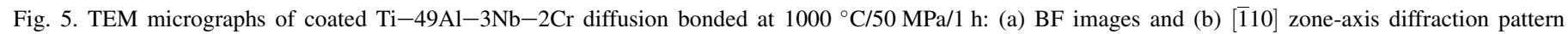
(I - base material, II - interlayer thin film). 
behaviour of the substrate alloys could explain this fact. Indeed, after compression tests of $50 \mathrm{~N}$ at $600{ }^{\circ} \mathrm{C}$, alloy A attained a deformation of $0.68 \%$, while for alloy B a $1.14 \%$ deformation was observed. Thus, diffusion bonding tests must be performed with coated $\mathrm{Ti}-49 \mathrm{Al}-3 \mathrm{Nb}-2 \mathrm{Cr}$ alloys at higher temperatures $\left(\geq 800{ }^{\circ} \mathrm{C}\right)$. A sound alloy $\mathrm{B}$ joint produced at $1000{ }^{\circ} \mathrm{C}$ is shown in Fig. 5. In the TEM images the substrate alloy and the interlayer thin film are perfectly distinguishable highlighting the excellent adhesion between them, while the bond-line is almost imperceptible. The difference in grain size is also noteworthy, the thin films being composed of nanometric and submicrometric grains $(80-300 \mathrm{~nm})$ after treatment at $1000{ }^{\circ} \mathrm{C}$, against $50-100 \mathrm{~nm}$ after treatment at $600{ }^{\circ} \mathrm{C}$ for $1 \mathrm{~h}$. Some diffusion bonding tests with alloy $\mathrm{B}$ have been performed at $800{ }^{\circ} \mathrm{C}$, so far with good results.

\section{Conclusions}

As-deposited Ti-48Al thin films, made up of alternate titanium and aluminium nanometric layers, evolve to a $\gamma$-TiAl major phase after heat treatment at $600{ }^{\circ} \mathrm{C}$. Based on this study, the heating cycle proposed for obtaining sound joints of bulk $\gamma$-TiAl is: $10{ }^{\circ} \mathrm{C} \mathrm{min}^{-1}$, maximum temperature $>600{ }^{\circ} \mathrm{C}$, holding time $\leq 1 \mathrm{~h}$. Using these Ti/Al thin films as interlayers it is possible to achieve sound joints on coated $\gamma$-TiAl alloys attesting to the feasibility of the methodology developed. For the success of the diffusion bonding process the microstructure and mechanical properties of the substrate material are determining factors. The grain size evolution with temperature and time during joining does not seem to be significant for the mechanical properties of the joints, but it will be necessary to evaluate them at high temperatures. The joining technology developed enlarges the applications of $\gamma$-TiAl and could be extrapolated to other intermetallics.

\section{Acknowledgements}

This work was supported by Fundação para a Ciência e Tecnologia, BPD/6771/2001, and FEDER.

\section{References}

[1] Kim Y-W. J Metals 1994;46:30.

[2] Alford TL, Gadre KS, Kim HC. Appl Phys Lett 2003;83:455.

[3] Leyens C, Schmidt M, Peters M, Kaysser WA. Mater Sci Eng A 1997;239-240:680.

[4] Coelho C, Ramos AS, Trindade B, Vieira MT, Fernandes JV, Vieira MF. Surf Coat Technol 1999;120/121:297.

[5] Vieira MT, Trindade B, Ramos AS, Fernandes JV, Vieira MF. Surf Coat Technol 2000;131:162.

[6] Vieira MT, Trindade B, Ramos AS, Fernandes JV, Vieira MF. Mater Sci Eng A 2002;329:146.

[7] Ramos AS, Vieira MT. Mater Sci Forum 2003;426(4):1843.

[8] Çam G, Koçak M. Int Mater Rev 1998;43:1.

[9] Nakao Y, Shinozaki K, Hamada M. ISIJ Int 1991;31:1260.

[10] Holmquist M, Recina V, Pettersson B. Acta Mater 1999;47:1791.

[11] Glatz W, Clemens H. Intermetallics 1997;5:415.

[12] Chaturvedi MC, Richards NL, Xu Q. Mater Sci Eng A 1997;240:605.

[13] Derby B, Wallach ER. Met Sci 1982;16:49.

[14] Yan P, Wallach ER. Intermetallics 1993;1:83.

[15] Ramos AS, Calinas R, Vieira MT. The formation of gamma-TiAl from Ti/Al multilayers with different periods. Surf Coat Technol, in press.

[16] Hampshire J, Kelly PJ, Teer DG. Thin Solid Films 2002;420-421:386.

[17] Michaelsen C, Wöhlert S, Bormann R. Mater Res Soc Symp Proc 1994;343:205.

[18] Buque C, Appel F. Z Metallkd 2002;93:784.

[19] Duarte LI, Ramos AS, Vieira MF, Viana F, Vieira MT. Z Mater Sci Forum 2006;516:1323. 